\title{
Effect of kefiran on mixolab thermomechanical properties of weak wheat dough
}

\begin{abstract}
Kefiran is an exopolysaccharide which is produced mainly by lactic acid bacteria and fungi in kefir grains during growth. In this study, Kefiran added at levels of $0.5,1$ and $1.5 \%$ w/w (flour basis) to wheat flour and its effects on the wheat dough behaviour subjected to a dual mechanical shear stress and temperature constraint using the Mixolab device have been studied. Results of Mixolab evaluation of dough showed that $1.5 \%$ Kefiran concentration induced the greatest benefits on wheat dough behaviour during mechanical shearing and thermal treatment resulting in a significantly increased water absorption, dough development time and stability and decreased dough departure time and stability during mixing. Increasing the amount of Kefiran from $0.5 \%$ to $1.5 \%$ increases in cooking stability, but dough maximum torqe (viscosity) increased or decreased significantly with increasing kefiran concentration, Nevertheless, dough thermal weakening and minimum torque did not change significantly $(\mathrm{P}<0.05)$. Increasing Kefiran $(1.5 \%$ concentration $)$ resulted in decreasing of protein weakening and gelatinization rates and also lowered the degree of starch breakdown which may be beneficial for bread with delayed tailing effects. Therefore, Kefiran may play an important role in improving of rheological properties of weak dough and its processing conditions.
\end{abstract}

Keywords: kefiran, weak wheat dough, mixolab
Volume 6 Issue 6 - 2017

\author{
Mansooreh Soleimani Fard,' Mehran Alami, ${ }^{2}$ \\ Aliraza Sadeghi Mahoonak, ${ }^{2}$ Mohammad \\ Omidnejad, ${ }^{3}$ Monireh Rahimi ${ }^{4}$ \\ 'Agriculture Faculty and Natural Resource of Gorgan, Iran \\ ${ }^{2}$ Department of Food Science and Technology, Iran \\ ${ }^{3}$ Department of low, Azad University of Doroud, Iran \\ ${ }^{4}$ Department of Food Science and Technology, Iran
}

\begin{abstract}
Correspondence: Mansooreh Soleimani Fard, Agriculture Faculty and Natural Resource of Gorgan, PhD of food chemistry, Gorgan Iran, Tel +098 919654 I882, Fax 017| 4450074,
\end{abstract} Email Mansoore.soleimani@yahoo.com

Received: March 28, 2017 | Published: July 07, 2017

\section{Introduction}

There is an increasing interest in the production of attractive and healthier foods with low fat content or with low levels of additives, ${ }^{1}$ but the replacements of additives in new functional foods, lowfat products or vegetarian foods have not been successful with consumers. ${ }^{2,3}$ This, the food industry is always searching for new food components to improve texture and mouth-feel of food; besides, a healthy promoting capacity is also required. ${ }^{4}$ In addition, the use of natural additive is being encouraged.

The objectives of their use to improve dough handling properties, increase quality of fresh bread and extend the shelf life of stored bread. ${ }^{5}$ Polysaccharides from several sources are used by the food industry as thickeners, emulsifiers and gelling agents. ${ }^{6}$ In addition, polysaccharides due to their high water retention capacity confer stability to the products that undergo successive freeze-thaw cycles. ${ }^{7,8}$ The polysaccharide from a bacterial source most widely used in foods systems is xanthan produced by Xanthomonas campestris, which is not considered a food grade microorganism. Kefiran, a microbial polysaccharide obtained from the flora of kefir grains, is finding increasing use in the food industry as a texturing and gelling agent. It is water-soluble polysaccharide containing approximately equal amounts of glucose and galactose. ${ }^{9}$

Also, when compared with other polysaccharides, Kefiran has several important advantages, such as antibacterial, antifungal, and antitumor properties. ${ }^{10,11}$ There is an increasing interest for natural additives in bakery that it result in has been increasing the use their in bakery industry. Exopolysaccharide produced from sourdough has been tested it's their ability as rheological properties improvers, it was worthy in increasing the water absorption capacity and decreased the dough softening after $20 \mathrm{~min}$ and resistance to extension after 45,90 and $135 \mathrm{~min}$ resting time. ${ }^{12}$ During the baking process, flour compounds are subjected to mechanical work and heat treatment that promote changes in their physicochemical properties. ${ }^{13}$ Mixing and pasting properties of wheat flour dough can be studied by Mixolab, which is a new tool capable of giving empirical rheological measurements of flour quality. The instrument allows analyzing the quality of the protein network and the starch behavior during heating and cooling. ${ }^{13-15}$ Also, Chunli Jia et al., ${ }^{16}$ studied thermal properties of oat dough by Mixolab analyzer. ${ }^{16}$

\section{Materials and methods}

\section{Materials}

Wheat whole Mill flour obtained from the Through Paris wheat sample $(10.56 \%$ moisture content, ash content, 7.20 dry gluten content, 362.33 falling number, 60.5 SDS-sedimentation value and $12.20 \%$ protein were determined using the methods of AACC, ${ }^{17}$ was collected (from farms of Alborz province, Iran) for the study. Initially kefir grains purchased locally were used in this study. Kefiran (1, 2 and $3 \%$ ) was used to prepare the dough formulations.

\section{Methods}

\section{Starter culture and fermentation medium}

Fresh kefir grains, used as starter culture in this study, were obtained from a household (Tehran, Iran). The grains were maintained at $20^{\circ} \mathrm{C}$ and were reactivated by successive subcultures in skimmed milk and dry milk (Golestan, Iran). Kefir grains, washed with sterile water, were inoculated $(10 \mathrm{~g})$ into $100 \mathrm{ml}$ of milk. After incubation at $24^{\circ} \mathrm{C}$ for $24 \mathrm{hr}$, the grains were separated from the fermented product by filtration through a plastic sieve (sanitized by immersion in $70 \%$ ethanol, and then washed with sterile water) and were washed prior to the next culture passage (subculture). Subcultures were repeated several times in order to increase kefir grain biomass. ${ }^{18}$ 


\section{Isolation and quantification of kefiran}

Exopolysaccharide in the kefir grains were extracted by the method of Piermaria et al. ${ }^{19}$ In briefly, a weighed amount of kefir grains was treated in boiling water $(1: 10 \mathrm{w} / \mathrm{w})$ for $30 \mathrm{~min}$ with discontinuous stirring. The mixture was centrifuged (Hanil Science Industrial, South Korea) at $10000 \mathrm{~g}$ min at $20^{\circ} \mathrm{C}$. The polysaccharide in the supernatant was precipitated by adding of an equal volume of cold ethanol and left at $20^{\circ} \mathrm{C}$ for overnight. The mixture was centrifuged at $10000 \mathrm{~g}$ for $20 \mathrm{~min}$ at $4^{\circ} \mathrm{C}$. Pellets were dissolved in hot water and the precipitation procedure was reported twice. The precipitate was finally dissolved in hot distilled water (kefiran solution) ${ }^{18,20}$ The resulting solution was concentrated by the freeze dryer (Operon, South Korea) and under vaccum oven (Memmert), yielding a crude polysaccharide. The samples were tested for the absence of other sugars and proteins by high-performance liquid chromatography and the phenol-sulphuric acid method, ${ }^{21}$ respectively.

\section{Rheological and thermo mechanical measurements}

The rheological and enzymatic property of flour dough was studied using a Mixolab analyzer (Chopin, France) according to ICC 173 standard method (ICC, 2006). For the assays, 50g of wheat flour or wheat flour-kefiran blends (i.e., using $0 \%, 0.5 \%, 1.0 \%, 1.5 \%$, $\mathrm{w} / \mathrm{w}$, flour basis) with known moisture content were placed into the Mixolab analyzer bowl and mixed to obtain a dough of $75 \mathrm{~g}$. After tempering the solids, the water required for optimum consistency (1.1 $\mathrm{Nm}$ ) was added. Special attention was paid to the determination of the water absorption, in order to ensure the complete hydration of all the components.

The settings used in the test were $8 \mathrm{~min}$ at $30^{\circ} \mathrm{C}$ with a temperature increase of $4^{\circ} \mathrm{C} / \mathrm{min}$ until the mixture reached $90^{\circ} \mathrm{C}$; at this point, there was an $8 \mathrm{~min}$ holding period at $90^{\circ} \mathrm{C}$, followed by a temperature decrease of $4^{\circ} \mathrm{C} / \mathrm{min}$ until the mixture reached $55^{\circ} \mathrm{C}$, and then $6 \mathrm{~min}$ of holding at $55^{\circ} \mathrm{C}$. The mixing speed during the entire assay was $73 \mathrm{rpm}$. The process was repeated twice for each blend as well as for the control. The parameters that for obtained from the recorded curve were Mixolab parameters were Mixolab water absorption
(MWA), Mixolab development time (MDT), Mixolab stability time (MST), Mixolab departure time (MDT), and Mixolab minimum torque (MMT), Mixolab peak temperature (MTP), temperature at the peak torque, Mixolab peak torque (MPT), Mixolab cooking stability (MCS), Mixolab thermal weakening (MTW), and Mixolab setback (MSB). MMT measures the weakening of the protein due to the mechanical work and the temperature. MTP, MPT, MBD, and MSB measure starch gelatinization and retro gradation profile. In addition, the slopes of ascending and descending torques and the angle between ascending and descending curves were calculated. Those angles were then used to determine $\alpha, \beta$, and $\gamma$, which correspond to the arc tangent of the three curve angles, respectively. The calculations were repeated two times for each blend. Detailed description of Mixolab parameters could also be found in a previous research reported by Koksel $\mathrm{H}$ et $\mathrm{al}^{22}$

\section{Statistical analysis}

The analysis of variance (ANOVA) and least significant difference (Duncan) were used to analyze the effect of kefiran on the dough characteristics and technological, textural and sensory properties of bulky bread. All statistical analyses were conducted at a significance level of $95 \%$ with the Statistical Analysis System for Windows (SPSS, Var 16.00).

\section{Results and discussion}

\section{Mixing and pasting properties of wheat dough determined in the Mixolab}

\section{Effect of kefiran on the wheat dough mixing properties}

The Mixolab mixing properties of dough containing different amount of kefiran are shown in Table 1. Water absorption (MWA) and dough development time (MDT) were significantly increased in the presence of kefiran. Probably, kefiran structure is prompted to interact with the wheat proteins through hydrogen bonds and hydrophobic interactions, this effect agreed with earlier findings Rosell, Hadnadev. ${ }^{13,23}$

Table I Comparison of the effect of levels of kefiran on thermomechanical properties of weak wheat flour

\begin{tabular}{|c|c|c|c|c|c|}
\hline \multirow{2}{*}{ Factor } & \multicolumn{5}{|c|}{ Mixolab parameter } \\
\hline & $\begin{array}{l}\text { Water } \\
\text { Absorption (\%) }\end{array}$ & $\begin{array}{l}\text { Development } \\
\text { Time(min) }\end{array}$ & $\begin{array}{l}\text { Departure } \\
\text { Time(min) }\end{array}$ & $\begin{array}{l}\text { Stability } \\
\text { Time(min) }\end{array}$ & $\begin{array}{l}\text { Amplitude } \\
\text { Torque(nm) }\end{array}$ \\
\hline Constant & $50.50 d$ & $1.05^{b}$ & $6.62^{\mathrm{a}}$ & $5.50^{\mathrm{a}}$ & $0.07^{a}$ \\
\hline $0.5 \%$ Kefiran & $52.3^{c}$ & $1.07^{\mathrm{ab}}$ & $7.67^{\mathrm{a}}$ & $6.23^{\mathrm{a}}$ & $0.1 I^{a}$ \\
\hline I\% Kefiran & $55.4^{b}$ & $1.06^{\mathrm{ab}}$ & $4.85^{b}$ & $3.42^{\mathrm{b}}$ & $0.10^{\mathrm{a}}$ \\
\hline I.5\% Kefiran & $58.6^{a}$ & $1.12^{\mathrm{a}}$ & $3.84^{b}$ & $2.40^{c}$ & $0.06^{a}$ \\
\hline R-sq & 95.7 & 95.7 & 93.2 & 65.6 & - \\
\hline
\end{tabular}

Different letters in each column shows statically values $(p \leq 0.5)$ 
The obtained Mixolab curves of wheat flour as well as the dough formulation supplemented with kefiran are presented in (Figure 1). By observing the first part of the curve, it can be seen that the increasing of kefiran concentration in the dough mixture resulted in weaker protein network in comparison to the mixing properties of system containing wheat flour alone. Therefore, with addition of kefiran concentration, dough stability (MST) and departure time (MDT) decreased (Table 1). Rosell, ${ }^{13}$ Hadnadev et al. ${ }^{23}$ Torbica, ${ }^{24}$ Moreira ${ }^{25}$ reported the reverse results in relation to effect of kefiran on MST in Farinograph machine. With decreasing MST and MDT, dough elasticity of tested system, expressed by the values of amplitude ( $\mathrm{Nm}$ ), decreased in the Mixolab analyzer, but the change was not p-value significant. This observation indicated that dough containing amount of hydroxypropylmethyl cellulose (HPMC), xanthan and guar gum, ${ }^{24,25}$ could be decreased MST and MDT and finally the dough elasticity properties of the product.

\section{Effect of kefiran on the wheat dough properties during heating}

By increasing and then decreasing the temperature, the following changes were observed: a higher cooking stability (MCS) and peak torque (MPT) and lower cooking stability (MCS) (kefiran 0.5\% concentration) comparing to control sample (Table 2). Also the data indicated that both addition of kefiran and increasing of temperature, dough thermal weakening (MTW) did not change significantly $(\mathrm{P}<0.05)$, whereas Rosell et al. ${ }^{13}$ reported difference results related to effect of hydroxypropylmethylcellulose (HPMC) about dough thermal weakening during increasing of temperature. In the cereal starch pastes, MCS has been related to stability of the already broken starch granules at the heating temperature. ${ }^{26}$ In the weak wheat dough, the MCS investigated in the presence of kefiran, resulting in an increase of $0.32 \%$ when $1.5 \%$ of kefiran was added (Table 2), the behaviour of the kefiran at $1.5 \%$ agrees with previous results obtained with mixture of hydrocolloids, transglutaminase and wheat flour system. ${ }^{13,15}$ During increase of temperature, the swelling and gelatinization of the starch granules occurred until the physical dissociation of the granules was accompanied by a decline in the torque, a further increment in the torque when the temperature decreased was associated with the recrystallization of the starch and was related to the retro gradation of the starch molecules (Figure 1-4). At the kefiran level of $1.5 \%$, there is an increase in MCS. These results agreed with earlier findings. ${ }^{13,15}$

Table 2 Significant coefficients (95\% confidence interval) of the design factors (independent variables) of the stepwise regression fitting model for the pasting characteristics parameters from Mixo lab graph

\section{Mixolab parameter}

\begin{tabular}{|c|c|c|c|c|c|c|c|}
\hline \multirow{2}{*}{ Factor } & & & & & & & \\
\hline & $\begin{array}{l}\text { Temperature } \\
\text { at minimum } \\
\text { torque }(\mathrm{C} 0)\end{array}$ & $\begin{array}{l}\text { Minimum } \\
\text { torque } \\
(\mathrm{Nm})\end{array}$ & $\begin{array}{l}\text { Thermal } \\
\text { weakening } \\
(\mathrm{Nm})\end{array}$ & $\begin{array}{l}\text { Temperature at } \\
\text { peak torque }\end{array}$ & $\begin{array}{l}\text { Peak } \\
\text { torque } \\
(\mathrm{Nm})\end{array}$ & $\begin{array}{l}\text { Cooking } \\
\text { stability } \\
(\mathrm{Nm})\end{array}$ & $\begin{array}{l}\text { Set back } \\
\text { value } \\
(\mathrm{Nm})\end{array}$ \\
\hline Constant & $53.8^{c}$ & $0.41^{\mathrm{a}}$ & $0.64^{\mathrm{a}}$ & $86.8^{\mathrm{a}}$ & $2.59^{c}$ & $1.14^{\mathrm{ab}}$ & $1.48^{\mathrm{a}}$ \\
\hline $0.5 \%$ Kefiran & $55.8^{\mathrm{a}}$ & $0.47^{\mathrm{a}}$ & $0.6^{\mathrm{a}}$ & $60.80^{b}$ & $4.75^{a}$ & $0.99^{\circ}$ & $0.09^{b}$ \\
\hline I\% Kefiran & $54.6^{\mathrm{b}}$ & $0.40^{\mathrm{a}}$ & $0.66^{\mathrm{a}}$ & $87^{a}$ & $2.82^{\mathrm{b}}$ & $1.25^{\mathrm{ab}}$ & $1.93^{\mathrm{a}}$ \\
\hline I.5\% Kefiran & $53.7^{\mathrm{bc}}$ & $0.41^{\mathrm{a}}$ & $\left.0.7\right|^{\mathrm{a}}$ & $87.8^{a}$ & $3^{b}$ & $1.46^{\mathrm{a}}$ & $1.84^{a}$ \\
\hline
\end{tabular}

Values are the average of three replicates from four different samples; different letters in the same row indicate significant differences $p<0.05$

\section{Derived parameters from the mixing-heating profiles}

Derived parameters from the heating-cooling cycle obtained Mixolab profiles (Figure 1-4), like rate of protein weakening $(\alpha)$, gelatinization rate $(\beta)$ as well as enzymatic degradation rate or starch breakdown $(\gamma)$ are also presented in Table 3. Generally, it is noticed that the presence of kefiran slightly affected these parameters. With addition of kefiran concentration, no significant difference was observed during protein weakening $(\alpha)$. The value of $\beta$ slope showed no significant differences at 0.5 and $1 \%$ kefiran concentration in comparison to control sample but increased significantly with addition of $1.5 \%$ kefiran concentration p-value. The increase of kefiran concentration induced a significant effect on dough behaviour during the enzymatic (amylase) degradation of starch stage $(\gamma)$ respect to control sample and also, significant difference was showed overall gelatinization of the starch stage $(\gamma)$. These behaviour of the kefiran reverse with previous results obtained with mixture of hydrocolloids and wheat flour system, ${ }^{13}$ but these results agreed with earlier findings. ${ }^{15}$

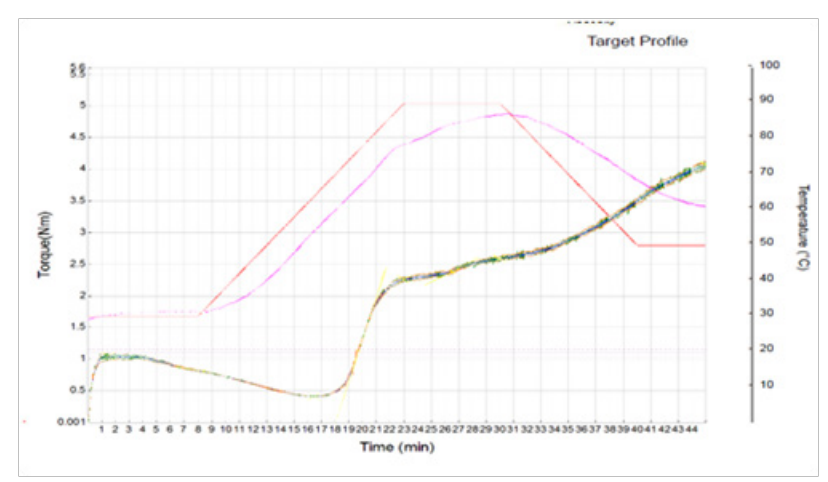

Figure I Mixolab profiles of wheat flour and dough supplements containing Control sample. 


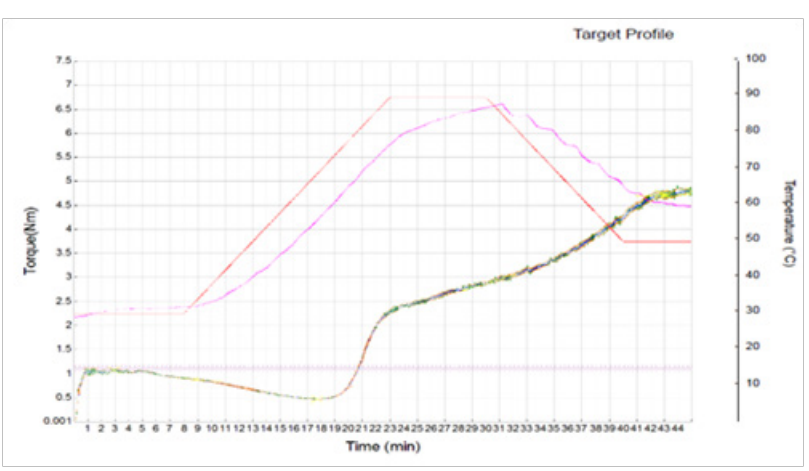

Figure 2 Mixolab profiles of wheat flour and dough supplements containing $0.5 \%$ kefiran.

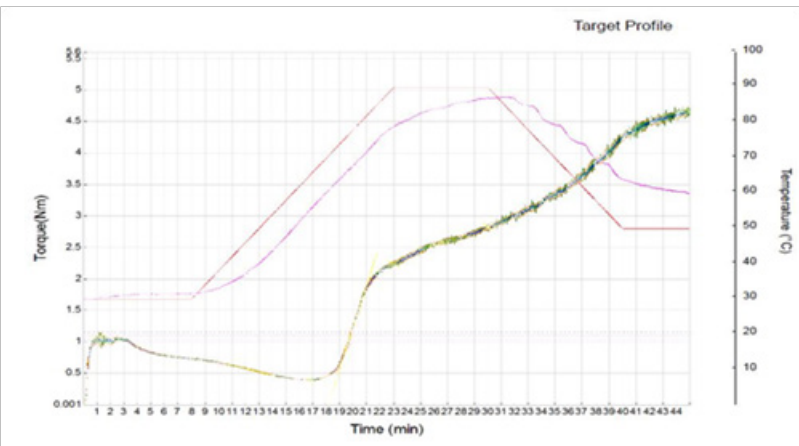

Figure 3 Mixolab profiles of wheat flour and dough supplements containing I\% Kefiran.

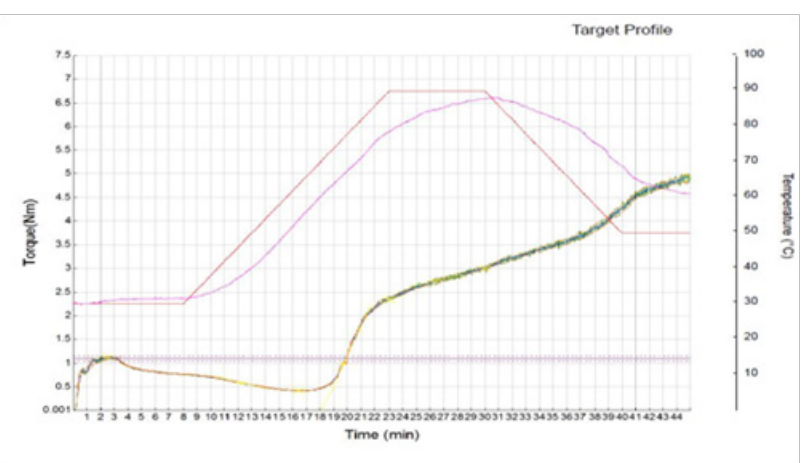

Figure 4 Mixolab profiles of wheat flour and dough supplements containing I.5\% Kefiran.

Table 3 Significant coefficients ( $95 \%$ confidence interval) of the design factors (independent variables) of the stepwise regression fitness model for the derived parameters obtained from Mixolab graph

\begin{tabular}{llll}
\hline & \multicolumn{2}{l}{ Derived parameter } \\
\cline { 2 - 4 } Factor & $\mathbf{a}(\mathbf{0 . 0 I})$ & $\boldsymbol{\beta}$ & $\gamma$ \\
\hline Constant & $-0.038 \mathrm{ab}$ & $0.660 \mathrm{a}$ & $0.110 \mathrm{a}$ \\
0.5\% Kefiran & $-0.022 \mathrm{a}$ & $0.686 \mathrm{a}$ & $0.08 \mathrm{ab}$ \\
I\% Kefiran & $-0.052 \mathrm{ab}$ & $0.664 \mathrm{a}$ & $0.060 \mathrm{~b}$ \\
I.5\% Kefiran & $-0.070 \mathrm{~b}$ & $0.328 \mathrm{~b}$ & $0.064 \mathrm{~b}$ \\
R-sq & 46.4 & 38.2 & 71 \\
\hline
\end{tabular}

Values are the average of three replicates from four different samples; different letters in the same row indicate significant differences $p<0.05$

\section{Conclusion}

The present study showed that addition of kefiran improved some rheological properties of dough. The kefiran $0.5 \%$ and $1.5 \%$ concentration was the hydrocolloid that causes the greatest effect on the wheat dough subjected to mechanical shearing and temperature constraint. Also, increasing kefiran content resulted in increased water absorption and development time content. Besides that, decreased stability and departure time, nevertheless, dough amplitude torque did not change significantly $(\mathrm{P}<0.05)$.

Peak torque and cooking stability (kefiran $1.5 \%$ ) was increased by addition of different kefiran concentrations. No significant effect was observed during set back and thermal weakening of the dough system. It is necessary to determine both rheological properties and sensory properties to achieve optimal formulation for the bakery product.

\section{Acknowledgements}

This research was financially supported by Kaladaran and MAX international Company (Tehran, Iran) Agriculture Faculty and Natural Resource of Gorgan (Gorgan, Iran) and Seed and Plant Improvement Institute of Alborz Province, chemistry laboratory (Karaj, Iran).The authors would like to gratefully acknowledge Dr. Mehran Ghasemlou for their cooperation during this study.

\section{Conflict of interest}

Author declares that there is no conflict of interest.

\section{References}

1. Welman AD, Maddox IS. Exopolysaccharides from lactic acid bacteria: perspectives and challenges. Trends Biotechnology. 2003;21(6):269-274.

2. Duboc P, Mollet B. Applications of exopolysaccharides in the dairy industry. International Dairy Journal. 2001:11759-11768.

3. Tárrega A, Costell E, Rao MA. Vane yield stress of native and crosslinked starch dispersions in skimmed milk: effect of starch concentration and $\lambda$-carrageenan addition. Food Science and Technology International. 2006;12(3):253-260.

4. Roberfroid MB. Concepts in Functional Foods: The Case of Inulin and Oligofructose. J Nutr. 1999;129(7 Suppl):1398-1401.

5. Rosell CM, Rojas JA, Benedito, et al. Influence of hydrocolloids on dough rheology and bread quality. Food Hydrocolloids. 2001;15:75-81.

6. De Vuyst L, Degeest B. Heteropolysaccharides from lactic acid bacteria. FEMS Microbiol Rev. 1999;23(2):153-177.

7. Lee MH, Baek MH, Cha DS, et al. Freeze - thaw stabilization of sweet potato starch gel by polysaccharide gums. Food Hydrocolloid. 2002;16:245-352.

8. Sanderson GR. Gums and their use in food systems. Food Technology. 1996;50:81-84.

9. Micheli L, Uccelletti D, Palleschi C, et al. Isolation and characterisation of a ropy Lactobacillus strain producing the exopolysaccharide kefiran. Appl Microbiol Biotechnol. 1999;53(1):69-74.

10. Maeda H, Zhu X, Omura K, et al. Effects of an exopolysaccharide (kefiran) on lipids, blood pressure, blood glucose, and constipation. Biofactors. 2004;22(1-4):197-200.

11. Murofushi M, Shiomi M, Aibara K. Effect of orally administered polysaccharide from kefir grain on delayed-type hypersensitivity and tumor growth in mice. Japanese Journal of Medical Science and Biology. 1983;36(1):49-53. 
12. Ketabi A, Soleimanian-Zad S, Kadivar M, et al. Production of microbia exopolysaccharides in the sourdough and its effects on the rheological properties of dough. Food Research International. 2008;41:948-951.

13. Rosell CM, Foegeding A. Interaction of hydroxypropylmethylcellulose with gluten proteins: Small deformation properties during thermal treatment. Food Hydrocolloids. 2007;21:1092-1100.

14. Abdel-Samie MA, Wan JJ, Huang WN, et al. Effects of cumin and ginger as antioxidants on dough mixing properties and cookie quality. Cereal Chemistry. 2010;87(5):454-460.

15. Huang WN, Li LL, Wang F, et al. Effect of transglutaminase on rheological and Mixolab thermo mechanical characteristics of oat dough. Food Chemistry. 2010;121:934-939.

16. Jia Ch, Huang W, Abdel-Shafi, et al. Dough rheological, Mixolab mixing, and nutritional characteristics of almond cookies with and without xylanase. Journal of Food Engineering. 2011;105:227-232.

17. Paul MN. Approved Methods of the American Association of Cereal Chemists. The Association, USA; 2002.

18. Rimada PS, Abraham AG. Polysaccharide production by kefir grains during whey fermentation. J Dairy Res. 2001;68(4):653-661.

19. Piermaria JA, Pinotti A, Garcia MA, et al. Films based on kefiran, an exopolysaccharide obtained from kefir grain: Development and characterization. Food Hydrocolloids. 2009;23:684-690.
20. Soleimanifard M, Aalami M, khodaiyan Chegeni F, et al. Production of kefiran in kefir grains and its effects on the rheological properties low protein wheat dough and quality of France bulky bread. Advances in Crop Science and Technology. 2015;3(4).

21. Dubois M, Gilles KA, Hamilton JK, et al. Colorimetric method for determination of sugars and related substances. Analytical Chemistry. 1956;38(3):350-352.

22. Koksel H, Kahraman K, Sanal T, et al. Potential utilization of Mixolab for quality evaluation of bread wheat genotypes. Cereal Chemistry. 2009;86(5):522-526.

23. Hadnađev M, Torbica A, Dokić P, et al. Influence of partial wheat flour substitution by buckwheat flour on dough rheology characteristics measured using Mixolab. Food Processing. 2008;35(3):129-134.

24. Torbica A, HadnaCev M, Dapcevic T. Rheological, textural and sensory properties of gluten-free bread formulations based on rice and buckwheat flour. Food Hydrocolloids. 2010;24(6-7):626-632.

25. Moreira R, Chenlo F, Torres MD. Rheology of commercial chestnu flour doughs incorporated with gelling agents. Food Hydrocolloid. 2011;25:1361-1371

26. Rojas JA, Rosell CM, Benedito C. Pasting properties of different wheat flour-hydrocolloid systems. Food Hydrocolloid. 1999;13:27-33. 